\title{
Role of Platelet-Activating Factor and Prostanoids in Hemodynamic Changes in Rat Experimental Endotoxic Shock
}

\author{
Tsuneyuki Ebara ${ }^{1}$, Katsuyuki Miura $^{1, *}$, Takeshi Matsuura $^{1}$, Masahito Imanishi $^{2}$, Yoshiki Yamano ${ }^{3}$, \\ Shokei Kim ${ }^{1}$ and Hiroshi Iwao ${ }^{1}$ \\ 'Department of Pharmacology and ${ }^{3}$ Department of Orthopaedic Surgery, Osaka City University Medical School, Osaka 545, Japan \\ ${ }^{2}$ Osaka City General Hospital, Osaka 534, Japan
}

Received February 13, 1996 Accepted April 23, 1996

\begin{abstract}
The present experiments were conducted to elucidate the role of platelet-activating factor (PAF) and cyclooxygenase products in the cardiovascular responses to endotoxin in anesthetized rats. Endotoxin $(10 \mathrm{mg} / \mathrm{kg}$, i.v. $)$ induced hypotension that was accompanied by a decrease in cardiac output and an increase in calculated total peripheral resistance, suggesting that this hypotension mainly resulted from the reduced cardiac output. The endotoxin-induced decrease in cardiac output and hemoconcentration was significantly attenuated by TCV-309 (a PAF receptor antagonist), ibuprofen (a cyclooxygenase inhibitor) or $\mathrm{S}-1452$ (a thromboxane $\mathrm{A}_{2}$ /prostaglandin $\mathrm{H}_{2}$-receptor antagonist). During the 3-hr observation period following endotoxin administration, ibuprofen and S-1452 showed only early protection and TCV-309 showed late attenuation of the endotoxin-induced hypotension. Tachycardiac responses to endotoxin were only blocked by ibuprofen but not by TCV-309 or S-1452. These results suggest that both PAF and cyclooxygenase product(s), including thromboxane $\mathrm{A}_{2}$, mediate the decrease in cardiac output and hypotension in rat experimental endotoxic shock. Cyclooxygenase product(s) other than thromboxane $A_{2}$ or prostaglandin endoperoxide may be involved in the endotoxin-induced increase in heart rate.
\end{abstract}

Keywords: Endotoxin, Platelet-activating factor, Cyclooxygenase, Hemodynamics

Endotoxin, the lipopolysaccharide associated with the outer cell membrane of gram-negative bacteria, causes a shock-like state characterized by severe hypotension, respiratory dysfunction and disseminated intravascular coagulation (1). A number of mediators such as cytokines, PAF, nitric oxide and arachidonic acid metabolites were shown to be involved in the pathogenetic sequences in endotoxic shock $(2,3)$. In anesthetized dogs, we previously reported that endotoxin induced hypotension by decreasing both total peripheral resistance and cardiac output. The cyclooxygenase inhibitor ibuprofen blocked the hypotension by increasing total peripheral resistance, whereas the PAF receptor antagonist TCV-309 increased cardiac output without affecting total peripheral resistance (4). In rats, both the cyclooxygenase inhibitor and PAF receptor antagonist attenuated endotoxin-induced hypotension and survival rate $(5,6)$, but the mode of action of these drugs on endotoxin-induced hemodynamic disturbance was poorly

\footnotetext{
* To whom correspondence should be addressed.
}

understood. Although both cardiac output and peripheral vascular tone are determinants of blood pressure, they were not separately considered when these blockers were tested in rat endotoxic shock. This is possibly due to the small size of the animal, although rats have been frequently used as an experimental model of endotoxic shock. Most of the detailed hemodynamic studies were conducted in large animals, such as dogs, sheep or swine $(4,7-9)$. However, it is well-known that the circulatory changes produced by endotoxin vary significantly among species (10). Therefore, the present experiment was conducted to examine the role of PAF and cyclooxygenase products in the systemic hemodynamic responses to endotoxin by successive measurement of cardiac output in anesthetized rats.

\section{MATERIALS AND METHODS}

\section{Animal preparation}

Male Sprague-Dawley rats (Charles River Japan, Inc., Osaka) weighing $260-330 \mathrm{~g}$ were used. Before the experi- 
ment, the animals were fasted overnight with free access to water. For the experiment, the rats were anesthetized by intraperitoneal injections of thiopental sodium (120 $\mathrm{mg} / \mathrm{kg}$ ). The rectal temperature was controlled at $38^{\circ} \mathrm{C}$ by a heating blanket and a lamp (ATB-1100; Nihon Kohden, Tokyo). The trachea was cannulated to facilitate respiration. The left femoral artery was cannulated for blood sampling, and the systemic blood pressure (BP) and heart rate (HR) were monitored continuously with a pressure transducer (400T, Nihon Kohden). A catheter was placed into the left femoral vein for infusions of saline or drug solutions at the rate of $4.5 \mathrm{ml} / \mathrm{kg} / \mathrm{hr}$. Another catheter was placed into the right atrium through the right jugular vein. A thermosensor was placed in the ascending aorta above the aortic valve through the right carotid artery, and the other side was connected to a cardiac output computer (Cardiotherm 500-AC-R; Columbus Instruments, Columbus, OH, USA). At the end of each study, the catheters and thermosensor were checked visually to assure their proper placements. We measured cardiac output (in duplicate) using the thermodilution technique by a bolus injection of $100 \mu 1$ cold saline into the right atrium (11). Total peripheral resistance was calculated by dividing the mean arterial pressure by the cardiac output as previously described (11). Blood samples were collected into capillary tubes, and their hematocrit was determined in duplicate. After completion of the surgery, the rats were left for 60 to $90 \mathrm{~min}$ to stabilize hemodynamic parameters.

\section{Experimental procedure}

Protocol 1: We investigated the roles of PAF in the endotoxin-induced hemodynamic changes in the rats. After measuring control parameters, continuous intravenous infusion of TCV-309, a specific PAF receptor antagonist (12), (100 $\mu \mathrm{g} / \mathrm{kg}$ bolus followed by $500 \mu \mathrm{g} / \mathrm{kg} / \mathrm{hr})$ $(n=6)$ or vehicle (equal volume of saline) $(n=7)$ was started and continued to the end of the experiment. This dose of TCV-309 has proven to be sufficient to block PAF-induced hypotension (13). Thirty minutes after the start of TCV-309 or vehicle administration, endotoxin (E. coli 0127: B8) was injected intravenously at a dose of $10 \mathrm{mg} / \mathrm{kg}$. This dose of endotoxin was chosen as it causes circulatory shock states in rats (14).

Protocol 2: We investigated the roles of cyclooxygenase metabolites in the endotoxin-induced hemodynamic changes in rats. After measuring control parameters, continuous intravenous infusion of ibuprofen, a cyclooxygenase inhibitor $(12.5 \mathrm{mg} / \mathrm{kg}$ bolus followed by 12.5 $\mathrm{mg} / \mathrm{kg} / \mathrm{hr})(\mathrm{n}=6), \mathrm{S}-1452$, a specific receptor antagonist of thromboxane $\mathrm{A}_{2} /$ prostaglandin $\mathrm{H}_{2} \quad(15), \quad(1.3 \mu \mathrm{g} / \mathrm{kg}$ $/ \min )(n=6)$ or vehicle (equal volume of saline) $(n=9)$ was started and continued to the end of the experiment.
Thirty minutes after the start of inhibitor or vehicle administration, endotoxin (E. coli 0127: B8) was injected intravenously at a dose of $10 \mathrm{mg} / \mathrm{kg}$. This dose of ibuprofen is enough to block the endotoxin-induced increase in prostaglandin release (5), and S- 1452 blocks U46619 (Thromboxane $\mathrm{A}_{2}$ mimetic)-induced hypertension (16).

In both Protocol 1 and Protocol 2, the cardiac output and hematocrit were measured before the pretreatments of the inhibitors, just before the bolus injection of the endotoxin, and at $15,30,60,90,120,150$ and $180 \mathrm{~min}$ after the injection.

\section{Drugs}

The following drugs were dissolved in $0.9 \%$ saline and administered intravenously: endotoxin (Difco Laboratories, Detroit, MI, USA), thiopental sodium (Tanabe Pharmaceuticals, Osaka), TCV-309 (3-bromo-5-[Nphenyl- $N$-[2-[[2-(1,2,3,4-tetrahydro-2-isoquinolyl-carbonyloxy) ethyl] carbamoyl] ethyl] carbamoyl] - 1 - propylpyridinium nitrate) (donated by Takeda Chemical Industry, Osaka), ibuprofen (donated by Kaken Pharmaceutical Co., Tokyo) and S-1452 (sodium $5(z)-1 R, 2 S, 3 S, 4 S-7-[3-$ phenylsulfonylamino bicyclo[2.2.1]hept-2-yl]-5-heptenoate hydrate) (donated by Shionogi \& Co., Ltd., Osaka).

\section{Statistics}

Data are expressed as the mean \pm S.E.M. For comparisons among groups, delta changes from pre-endotoxin infusion values were analyzed by one way analysis of variance. For the time course effects, the measured values were analyzed by using the randomized block analysis of variance. Individual comparisons were made by the Duncan new multiple range test. A value of $P<0.05$ was considered statistically significant.

\section{RESULTS}

There were no statistical differences in the baseline values of hemodynamic parameters among the groups. Pretreatment with any of the inhibitors did not affect these parameters (Table 1).

\section{Protocol 1}

The bolus injection of endotoxin induced a progressive hypotension and a decrease in cardiac output. The blood pressure and cardiac output decreased from $118 \pm 3$ to $74 \pm 13 \mathrm{mmHg}$ at $180 \mathrm{~min}$ and from $32.4 \pm 1.6$ to $13.8 \pm 1.4 \mathrm{ml} / \mathrm{min} / 100 \mathrm{~g}$ at $180 \mathrm{~min}$ after the endotoxin administration, respectively. On the other hand the total peripheral resistance increased from $3.69 \pm 0.19$ to $6.37 \pm 0.41 \mathrm{mmHg} \cdot \mathrm{min} \cdot 100 \mathrm{~g} / \mathrm{ml}$ at $30 \mathrm{~min}$ and then declined toward the control value. In response to 
Table 1. Hemodynamic values before and after administration of inhibitors

\begin{tabular}{|c|c|c|c|c|c|c|}
\hline & & \multicolumn{2}{|c|}{ Protocol 1} & \multirow[b]{2}{*}{ Vehicle } & \multicolumn{2}{|l|}{ Protocol 2} \\
\hline & & Vehicle & TCV-309 & & Ibuprofen & S-1452 \\
\hline $\mathrm{n}$ & & 7 & 6 & 9 & 6 & 6 \\
\hline \multirow[t]{2}{*}{$\mathrm{BP}(\mathrm{mmHg})$} & before & $121 \pm 4$ & $120 \pm 4$ & $125 \pm 4$ & $128 \pm 4$ & $119 \pm 5$ \\
\hline & after & $118 \pm 3$ & $125 \pm 4$ & $122 \pm 4$ & $119 \pm 5$ & $114 \pm 5$ \\
\hline \multirow[t]{2}{*}{ HR (beats/min) } & before & $392 \pm 14$ & $367 \pm 13$ & $360 \pm 14$ & $366 \pm 6$ & $355 \pm 10$ \\
\hline & after & $392 \pm 12$ & $365 \pm 12$ & $361 \pm 14$ & $357 \pm 8$ & $355 \pm 9$ \\
\hline \multirow[t]{2}{*}{$\mathrm{CO}(\mathrm{ml} / \mathrm{min} / 100 \mathrm{~g})$} & before & $34.0 \pm 1.3$ & $34.5 \pm 1.1$ & $30.5 \pm 1.9$ & $31.6 \pm 1.7$ & $34.3 \pm 0.7$ \\
\hline & after & $32.4 \pm 1.6$ & $32.4 \pm 2.2$ & $28.9 \pm 1.5$ & $31.6 \pm 1.1$ & $32.6 \pm 0.5$ \\
\hline \multirow[t]{2}{*}{$\mathrm{TPR}(\mathrm{mmHg} \cdot \min \cdot 100 \mathrm{~g} / \mathrm{ml})$} & before & $3.61 \pm 0.22$ & $3.50 \pm 0.14$ & $4.21 \pm 0.24$ & $4.14 \pm 0.35$ & $3.46 \pm 0.11$ \\
\hline & after & $3.69 \pm 0.19$ & $3.93 \pm 0.31$ & $4.28 \pm 0.21$ & $3.78 \pm 0.20$ & $3.48 \pm 0.13$ \\
\hline \multirow[t]{2}{*}{$\mathrm{Ht}\left(\boldsymbol{v}_{0}\right)$} & before & $48.4 \pm 1.1$ & $47.2+0.7$ & $50.4 \pm 0.8$ & $48.5 \pm 1.0$ & $49.9 \pm 1.0$ \\
\hline & after & $48.3 \pm 1.0$ & $46.5 \pm 0.6$ & $50.4 \pm 0.7$ & $47.8 \pm 0.9$ & $49.4 \pm 1.0$ \\
\hline
\end{tabular}

Values are given as means \pm S.E.M. BP, blood pressure; HR, heart rate; CO, cardiac output; TPR, total peripheral vascular resistance; $\mathrm{Ht}$, hematocrit; before, before inhibitor or vehicle administration; after, 30 min after the beginning of vehicle or inhibitor administration (just before endotoxin administration).

endotoxin, the hematocrit rose from $48.3 \pm 1.0 \%$ to $58.7 \pm 1.4 \%$ at $30 \mathrm{~min}$ and decreased to $52.0 \pm 1.8 \%$ at $180 \mathrm{~min}$. The heart rate increased from $392 \pm 12$ beats $/ \mathrm{min}$ to $465 \pm 14$ beats $/ \mathrm{min}$ at $60 \mathrm{~min}$ and remained elevated during the entire course of the experiment. The endotoxin-induced hypotension was attenuated by TCV309 only at $180 \mathrm{~min}$, while the decrease in cardiac output was attenuated during the entire period after the endotoxin administration (except at $15 \mathrm{~min}$ ). The increase in the total peripheral resistance was significantly attenuated by TCV-309 at 30 and $60 \mathrm{~min}$ after the endotoxin administration. TCV-309 did not affect the endotoxin-induced increase in the heart rate. Endotoxin increased the hematocrit even in the presence of TCV-309, but the magnitude was statistically less than that without TCV309 (Fig. 1).

\section{Protocol 2}

The bolus injection of endotoxin caused similar hemodynamic changes that were observed in Protocol 1 (Fig. 2). The endotoxin-induced hypotension was attenuated shortly after the endotoxin administration by ibuprofen or S-1452. Significant attenuation of endotoxin-induced hypotension was observed at $30 \mathrm{~min}$ with ibuprofen. Although S-1452 tended to eliminate endotoxin-induced hypotension at $15 \mathrm{~min}$, this difference became statistically significant when examined as the percentage change in the blood pressure. With S-1452, endotoxin increased the blood pressure by $7.7 \pm 1.0 \%$, whereas endotoxin alone decreased by $8.5 \pm 4.9 \%$ $(\mathrm{P}<0.05$ compared to the values with S-1452). Neither blocker significantly affected the endotoxin-induced hypotension thereafter. In contrast, both ibuprofen and
S-1452 ameliorated the decrease in cardiac output in response to endotoxin at all the time points. The endotoxin-induced increase in total peripheral resistance was partially attenuated by ibuprofen or S-1452. Both ibuprofen and S-1452 attenuated the endotoxin-induced increase in hematocrit. With these inhibitors, the increase in hematocrit reverted to the baseline within 120 min after the endotoxin administration. Although S-1452 had no effect on the endotoxin-induced tachycardia, ibuprofen completely blocked the tachycardiac responses to endotoxin.

\section{DISCUSSION}

In the present experiments, we observed that the PAF receptor antagonist $\mathrm{TCV}-309$ markedly attenuated the endotoxin-induced reduction in cardiac output. Although studies with other species such as sheep or dogs showed that PAF antagonists blocked the reduction in cardiac output $(4,7,8)$, this is the first evidence in rats. Since TCV-309 also attenuated the endotoxin-induced rise in hematocrit, the inhibition of plasma extravasation would contribute to the recovery of reduced cardiac output. We previously showed that the dilatation of capacitance vessels by PAF led to blood pooling and resulted in the decrease in cardiac output following an endotoxin administration in anesthetized dogs $(4,16)$. A similar mechanism may operate in the present experiment, although we did not test the possibility. As a study with isolated perfused rat heart showed cardiac depression by PAF (17), blockade of cardiac action of PAF with the antagonist may attenuate the endotoxin-induced decrease in cardiac output.

In the present experiments, endotoxin elicited progres- 

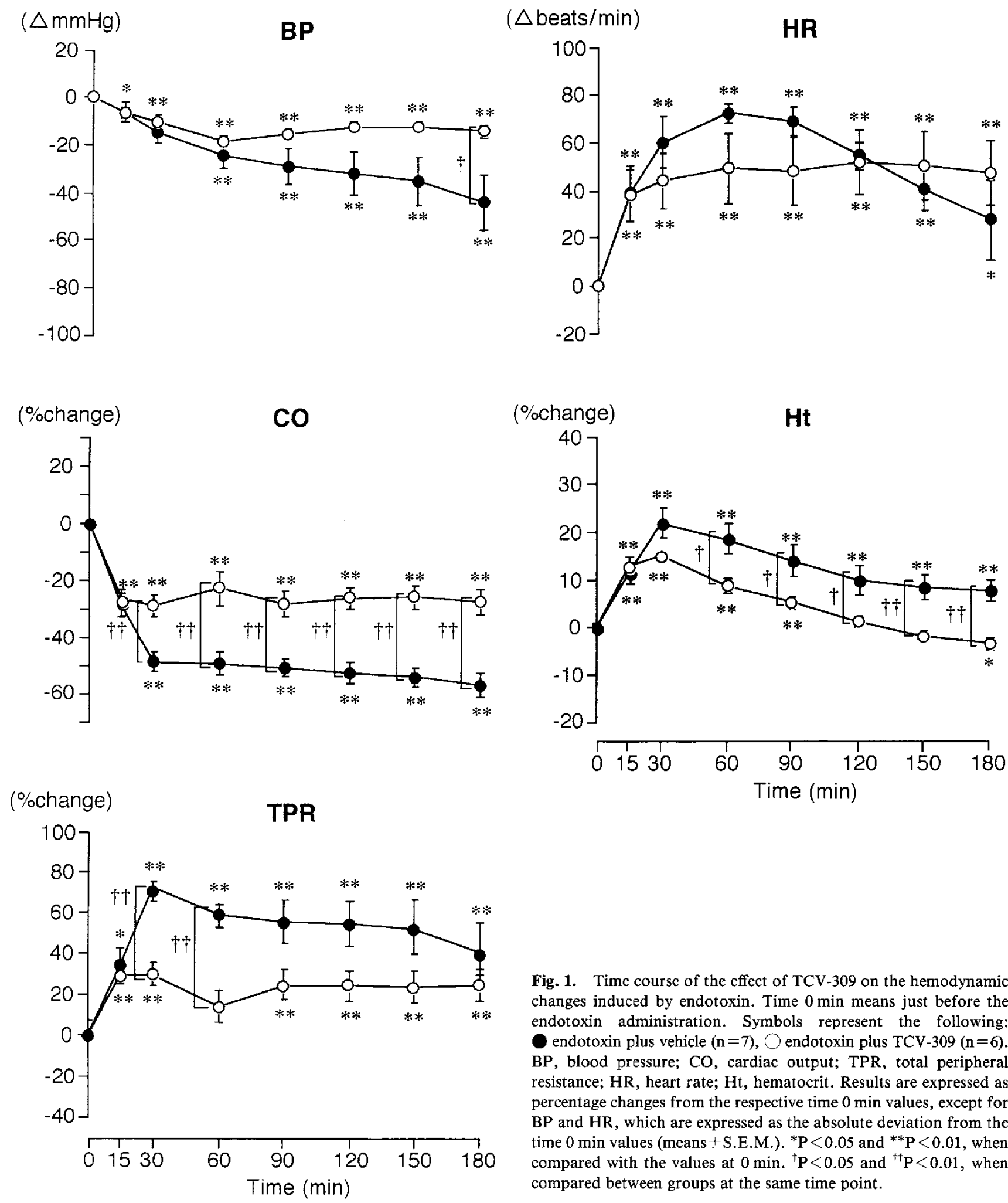

Fig. 1. Time course of the effect of TCV-309 on the hemodynamic changes induced by endotoxin. Time $0 \mathrm{~min}$ means just before the endotoxin administration. Symbols represent the following: endotoxin plus vehicle $(n=7)$, $\bigcirc$ endotoxin plus TCV-309 $(n=6)$. $\mathrm{BP}$, blood pressure; $\mathrm{CO}$, cardiac output; TPR, total peripheral resistance; $\mathrm{HR}$, heart rate; $\mathrm{Ht}$, hematocrit. Results are expressed as percentage changes from the respective time 0 min values, except for $\mathrm{BP}$ and $\mathrm{HR}$, which are expressed as the absolute deviation from the time 0 min values (means \pm S.E.M.). ${ }^{*} \mathrm{P}<0.05$ and ${ }^{* *} \mathrm{P}<0.01$, when compared with the values at $0 \mathrm{~min} .{ }^{\dagger} \mathrm{P}<0.05$ and ${ }^{+\top} \mathrm{P}<0.01$, when compared between groups at the same time point. 


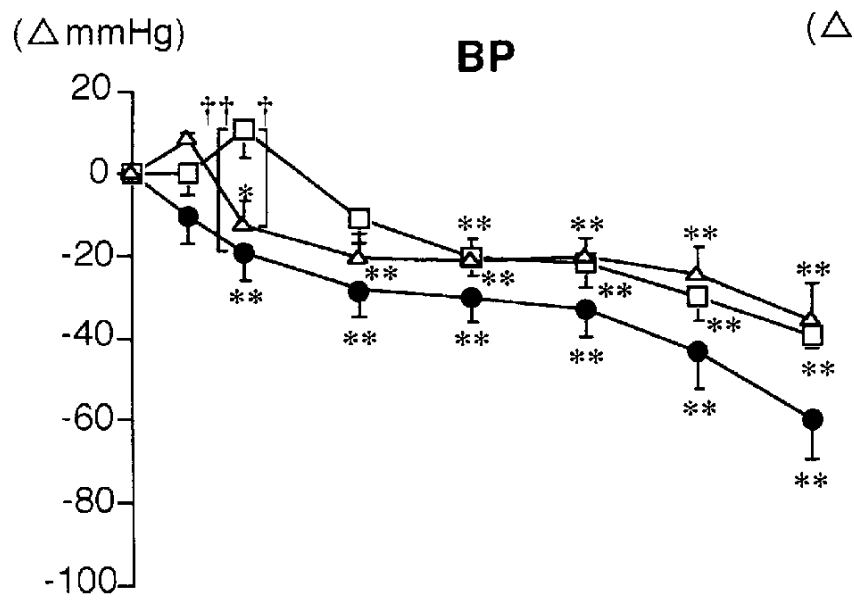

( $\triangle$ beats $/ \mathrm{min}$ )

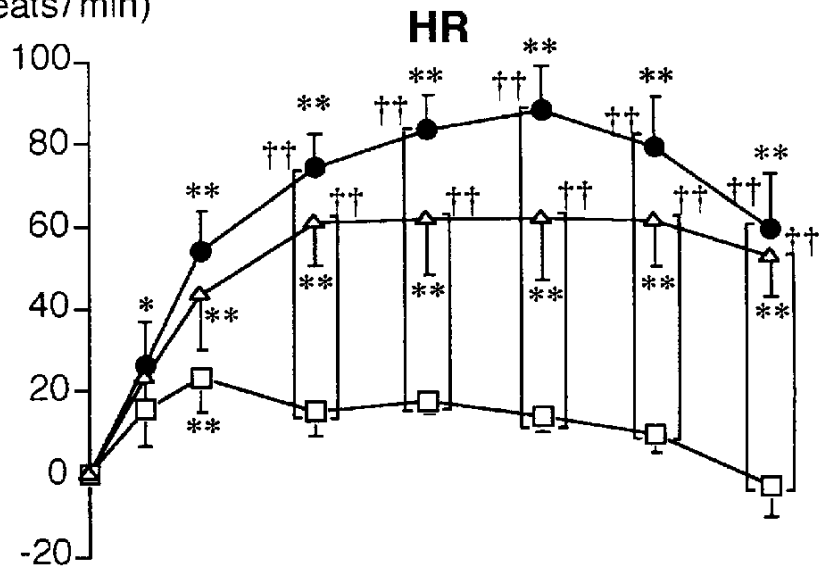

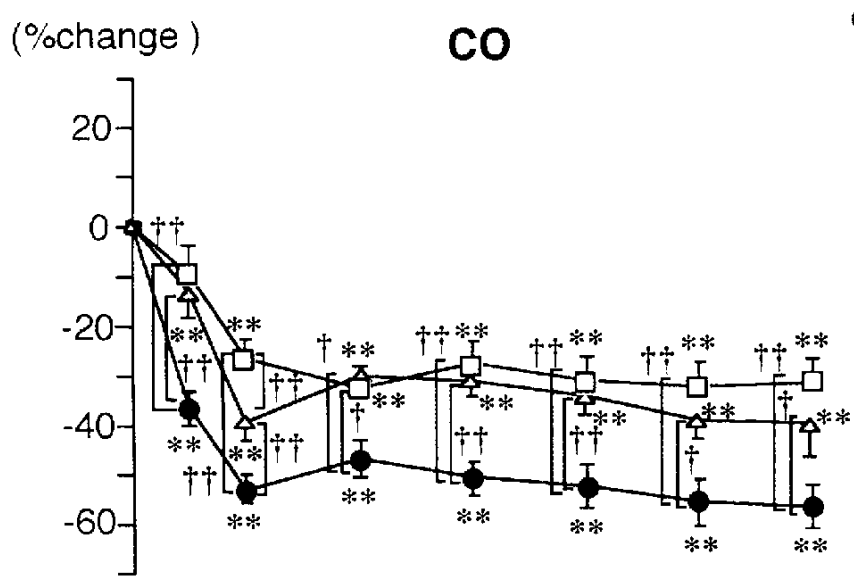

(\%change)

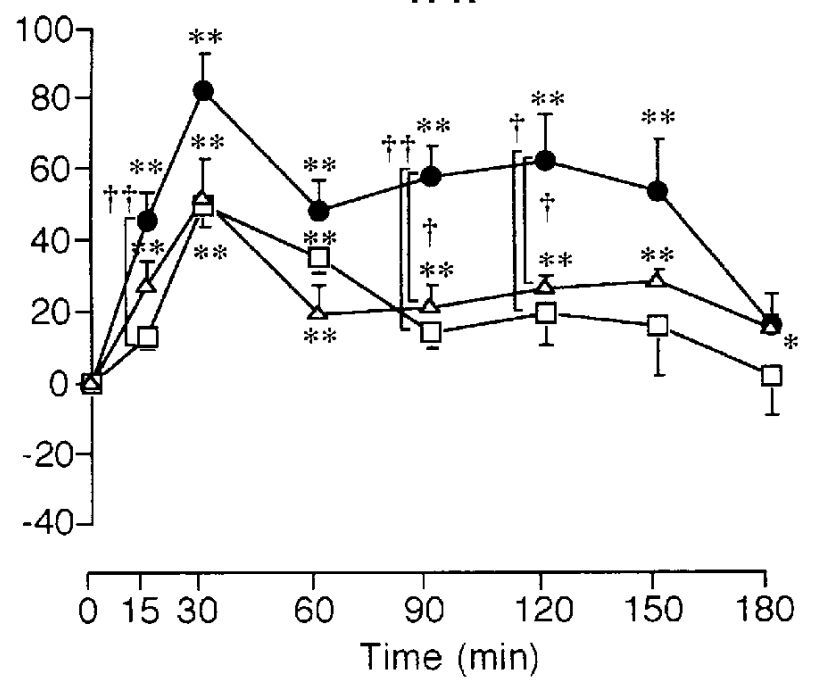

(\%change) Ht

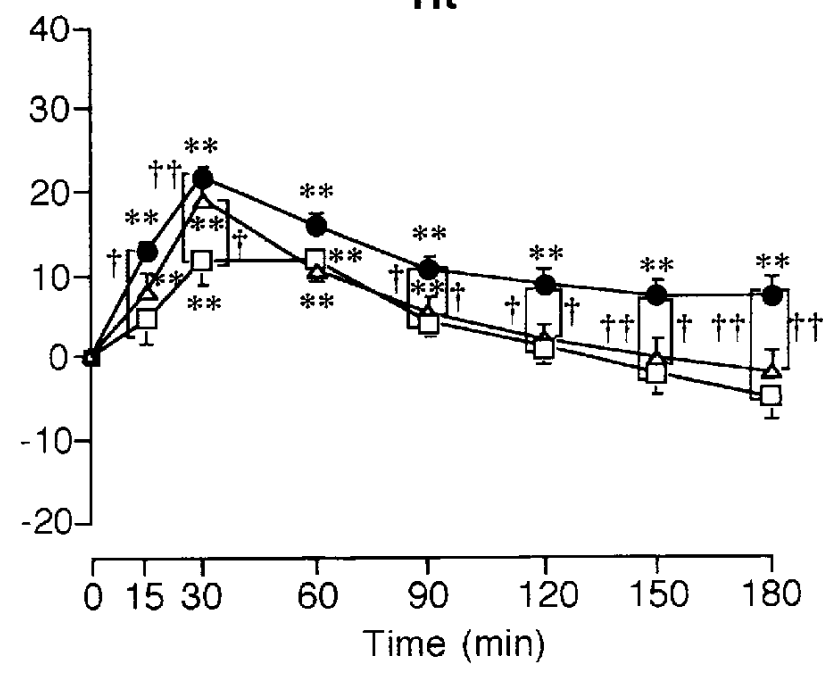

Fig. 2. Time course of the effect of ibuprofen and S-1452 on the hemodynamic changes induced by endotoxin. Time 0 min means just before the endotoxin administration. Symbols represent the following: endotoxin plus vehicle $(\mathrm{n}=9), \square$ endotoxin plus ibuprofen $(n=6), \triangle$ endotoxin plus S-1452 $(n=6)$. BP, blood pressure; $\mathrm{CO}$, cardiac output; TPR, total peripheral resistance; HR, heart rate; $\mathrm{Ht}$, hematocrit. Results are expressed as percentage changes from the respective time 0 min values, except for $B P$ and $H R$, which are expressed as the absolute deviation from the time 0 min values (means \pm S.E.M.). ${ }^{*} \mathrm{P}<0.05$ and ${ }^{* *} \mathrm{P}<0.01$, when compared with the values at 0 min. ${ }^{\dagger} \mathrm{P}<0.05$ and ${ }^{\dagger} P<0.01$, when compared between groups at the same time point. 
sive hypotension over $3 \mathrm{hr}$. Since the decrease in blood pressure was associated with the decrease in cardiac output and increase in calculated total peripheral resistance, this hypotension was attributable to the reduction in cardiac output. Qualitatively, similar results were reported in conscious rats (18). As TCV-309 attenuated the endotoxin-induced decrease in cardiac output, TCV-309 should have attenuated hypotension to a similar degree. Although TCV-309 improved cardiac output during the entire period after endotoxin administration (except at 15 min), it significantly attenuated the endotoxin-induced hypotension only at $180 \mathrm{~min}$. This discrepancy may arise from the fact that the endotoxin-induced increase in total peripheral resistance was significantly blocked by TCV309 between 30 and $60 \mathrm{~min}$. The rise in peripheral resistance by the endotoxin administration would have acted to maintain blood pressure. Although precise mechanisms of the increased total peripheral resistance are unknown, increased blood viscosity due to the hemoconcentration and the constriction of resistance vessels are both possibly involved. As the endotoxin-induced increase in hematocrit was attenuated by TCV-309, it may contribute to eliminate the increase in total peripheral resistance and prevent blood pressure recovery.

There are a number of reports describing the protective action of PAF antagonists on endotoxin-induced hypotension in rats, although the degree of protection and/or the time course were different $(6,11,14,19-22)$. In the present experiment, endotoxin-induced hypotension was only partially attenuated by the PAF antagonist, which is in marked contrast to the complete blockade reported by others $(6,13)$. Nevertheless, our data clearly showed TCV-309 improved the hypodynamic state in the rat experimental endotoxic shock.

It is well-known that endotoxic shock is associated with a remarkable increase in cyclooxygenase products $(5,23$, 24). Furthermore, cyclooxygenase products and PAF have close relationships in their production and biological activities $(25,26)$. Therefore, the roles of cyclooxygenase products were also examined pharmacologically in the present study. The blockade of cyclooxygenase with ibuprofen markedly attenuated the endotoxin-induced decrease in cardiac output. These results suggest that cyclooxygenase products were also involved in the endotoxininduced reduction in cardiac output. In the absence of the blocker, cardiac output decreased over $40 \%$ at $15 \mathrm{~min}$ after endotoxin, whereas it remained unchanged when rats were treated with ibuprofen. In addition to the sustained blockade of endotoxin-induced decrease in cardiac output, ibuprofen attenuated increases in hematocrit and total peripheral resistance by endotoxin. Since these hemodynamic effects of ibuprofen were basically the same as those of TCV-309, cyclooxygenase products and
PAF may share, at least in part, similar mechanisms of action on the endotoxin-induced hemodynamic alterations. These results were in a marked contrast to our previous findings in dogs. In anesthetized dogs, endotoxin induced hypotension that was accompanied by decreases in both cardiac output and total peripheral resistance. TCV-309 attenuated the former and ibuprofen blocked the latter (4). The discrepancy is possibly related to the well-known fact that circulatory changes produced by endotoxin vary among species (10).

$\mathrm{S}-1452$, a thromboxane $\mathrm{A}_{2}$ /prostaglandin $\mathrm{H}_{2}$-receptor antagonist, ameliorated the endotoxin-induced circulatory changes; this action is quite similar to that seen with ibuprofen. Thus, among the cyclooxygenase products, thromboxane $\mathrm{A}_{2}$ or prostaglandin endoperoxide may play a crucial role in the endotoxin-induced hemodynamic changes. This notion is supported by the report that thromboxane synthetase inhibitors attenuated the decrease in cardiac output induced by the administration of Salmonella endotoxin in conscious rats (27). From the present experimental results, it is difficult to elucidate the mechanism for how S-1452 attenuated the endotoxininduced reduction in cardiac output. The blockade of thromboxane-induced pulmonary hypertension by S-1452 may improve cardiac output as thromboxane $A_{2}$ elicited pulmonary hypertension and caused a reduction in cardiac output in sheep experimental endotoxic shock (28). However, this possibility is unlikely because administration of $E$. coli endotoxin at twice the dose that we used did not elicit pulmonary hypertension in rats (29). Since the endotoxin-induced increase in hematocrit was attenuated by S-1452, the preservation of circulating blood volume may contribute to the recovery of the reduced cardiac output. In addition to thromboxane $A_{2}$ or prostaglandin endoperoxide, other cyclooxygenase products may also be involved in the endotoxin-induced hemodynamic alteration. In this context, it is of note that ibuprofen but not $\mathrm{S}-1452$ blocked the endotoxin-induced tachycardia. These results suggest that prostaglandins other than thromboxane or prostaglandin endoperoxide increased the heart rate following endotoxin administration. In the present experimental setting, however, we do not know how prostaglandins increased the heart rate or whether it is a direct or secondary action of prostaglandins.

In summary, these results suggest that both PAF and a cyclooxygenase product(s), including thromboxane $\mathrm{A}_{2}$, mediate the decrease in cardiac output and hypotension in rat experimental endotoxic shock. Cyclooxygenase product(s) other than thromboxane $A_{2}$ or prostaglandin endoperoxide may be involved in the endotoxin-induced increase in heart rate. 


\section{Acknowledgments}

This work was supported in part by a Grant-in-Aid for Scientific Research (06672273) from the Ministry of Education, Science, Sports and Culture, Japan.

\section{REFERENCES}

1 Parrillo JE: Pathogenetic mechanisms of septic shock. N Engl $J$ Med 328, 1471 - 1477 (1993)

2 Morrison DC and Ryan JL: Endotoxins and disease mechanisms. Annu Rev Med 38, 417-432 (1987)

3 Szabo C: Alterations in nitric oxide production in various forms of circulatory shock. New Horiz 3, 2-32 (1995)

4 Yamanaka S, Iwao H, Yukimura T, Kim S and Miura K: Effect of the platelet-activating factor antagonist, TCV-309, and the cyclo-oxygenase inhibitor, ibuprofen, on the haemodynamic changes in canine experimental endotoxic shock. Br J Pharmacol 110, 1501-1507 (1993)

5 Wise WC, Cook JA, Eller T and Halushka PV: Ibuprofen improves survival from endotoxic shock in the rat. J Pharmacol Exp Ther 215, 160-164 (1980)

6 Terashita Z, Imura Y, Nishikawa K and Sumida S: Is platelet activating factor (PAF) a mediator of endotoxin shock? Eur $J$ Pharmacol 109, 257-261 (1985)

7 Kawamura M, Kitayoshi T, Terashita Z, Fujiwara S, Takatani $M$ and Nishikawa K: Effects of TCV-309, a novel PAF antagonist, on circulatory shock and hematological abnormality induced by endotoxin in dogs. J Lipid Mediat Cell Signal 9, 255-265 (1994)

8 Toyofuku T, Kubo K, Kobayashi T and Kusama S: Effects of ONO-6240, a platelet-activating factor antagonist, on endotoxin shock in unanesthetized sheep. Prostaglandins 31, 271-281 (1986)

9 Siebeck M, Weipert J, Keser C, Kohl J, Spannagl M, Machleidt $\mathrm{W}$ and Schweiberer L: A triazolodiazepine platelet activating factor receptor antagonist (WEB 2086) reduces pulmonary dysfunction during endotoxin shock in swine. J Trauma 31, 942-949 (1991)

10 Gilbert RP: Mechanisms of the hemodynamic effects of endotoxin. Physiol Rev 40, 245-279 (1960)

11 Siren AL and Feuerstein G: Effects of PAF and BN 52021 on cardiac function and regional blood flow in conscious rats. Am J Physiol 257, H25-H32 (1989)

12 Terashita Z, Takatani M, Nishikawa K: Pharmacological profile of TCV-309 - a potent PAF antagonist. J Lipid Mediat 5, $183-185$ (1992)

13 Terashita Z, Kawamura M, Takatani M, Tsushima S, Imura Y and Nishikawa K: Beneficial effects of TCV-309, a novel potent and selective platelet activating factor antagonist in endotoxin and anaphylactic shock in rodents. J Pharmacol Exp Ther 260, $748-755$ (1992)

14 Szabo C, Wu CC, Mitchell JA, Gross SS, Thiemermann C and Vane JR: Platelet-activating factor contributes to the induction of nitric oxide synthase by bacterial lipopolysaccharide. Circ Res 73, $991-999$ (1993)
15 Hirata M, Yanashi Y, Ushikubi F, Yokota Y, Kageyama R, Nakanishi $S$ and Narumiya $S$ : Cloning and expression of cDNA for a human thromboxane $A_{2}$ receptor. Nature 349, 617-620 (1991)

16 Yamanaka S, Miura $\mathrm{K}$, Yukimura $\mathrm{T}$, Okumura $\mathrm{M}$ and Yamamoto K: Putative mechanism of hypotensive action of platelet-activating factor in dogs. Circ Res 70, 893-901 (1992)

17 Pugsley MK, Salari H and Walker MJ: Actions of plateletactivating factor on isolated rat hearts. Circ Shock 35, 207-214 (1991)

18 Brackett DJ, Schaefer CF, Tompkins P, Fagraeus L, Peters LJ and Wilson MF: Evaluation of cardiac output, total peripheral vascular resistance, and plasma concentrations of vasopressin in the conscious, unrestrained rat during endotoxemia. Circ Shock 17, 273-284 (1985)

19 Rabinovici R, Yue TL, Farhat M, Smith E3, Esser KM, Slivjak $M$ and Feuerstein G: Platelet activating factor (PAF) and tumor necrosis factor-alpha (TNF alpha) interactions in endotoxemic shock: studies with BN 50739, a novel PAF antagonist. J Pharmacol Exp Ther 255, 256-263 (1990)

20 Qi $\mathrm{M}$ and Jones SB: Contribution of platelet activating factor to hemodynamic and sympathetic responses to bacterial endotoxin in conscious rats. Circ Shock 32, 153-163 (1990)

21 Doebber TW, Wu MS, Robbins JC, Choy BM, Chang MN and Shen TY: Platelet activating factor (PAF) involvement in endotoxin-induced hypotension in rats. Studies with PAF-receptor antagonist kadsurenone. Biochem Biophys Res Commun 127, 799-808 (1985)

22 Chang SW, Feddersen CO, Henson PM and Voelkel NF: Platelet-activating factor mediates hemodynamic changes and lung injury in endotoxin-treated rats. J Clin Invest 79 , $1498-1509$ (1987)

23 Ball HA, Cook JA, Wise WC and Halushka PV: Role of thromboxane, prostaglandins and leukotrienes in endotoxic and septic shock. Intensive Care Med 12, 116-126 (1986)

24 Cook JA, Wise WC and Halushka PV: Elevated thromboxane levels in the rat during endotoxic shock: protective effects of imidazole, 13-azaprostanoic acid, or essential fatty acid deficiency. J Clin Invest 65, 227-230 (1980)

25 Braquet $P$, Touqui L, Shen TY and Vargaftig BB: Perspectives in platelet-activating factor research. Pharmacol Rev 39, 97-145 (1987)

26 Chao $\mathrm{W}$ and Olson MS: Platelet-activating factor: receptors and signal transduction. Biochem J 292, 617-629 (1993)

27 Tempel GE, Cook JA, Wise WC, Halushka PV and Corral D: Improvement in organ blood flow by inhibition of thromboxane synthetase during experimental endotoxic shock in the rat. $J$ Cardiovasc Pharmacol 8, 514-519 (1986)

28 Redl G, Abdi S, Traber LD, Nichols RJ, Flynn JT, Herndon DN and Traber DL: Inhibition of thromboxane synthesis reduces endotoxin-induced right ventricular failure in sheep. Crit Care Med 19, 1294-1302 (1991)

29 Kirton OC, Jones RC and Carvalho AC: Thromboxane and prostacyclin release after endotoxin infusion in the rat. Intensive Care Med 16, 436-440 (1990) 